\title{
Rheological behavior and viscosity reduction of heavy crude oil and its blends from the Sui-zhong oilfield in China
}

\author{
Jian Zhang ${ }^{\mathrm{a}}$, Xiao-ping Chen ${ }^{\mathrm{a}}$, Dong Zhang ${ }^{\mathrm{a}, \mathrm{b}}$, Jing-yu $\mathrm{Xu}^{\mathrm{a}, \mathrm{b}, *}$ \\ ${ }^{a}$ Institute of Mechanics, Chinese Academy of Sciences, Beijing 100190, China \\ ${ }^{\mathrm{b}}$ School of Engineering Sciences, University of Chinese Academy of Sciences, Beijing 100049, China
}

\section{A R T I C L E I N F O}

\section{Keywords:}

Heavy crude oil

Pipeline transportation

Rheological behavior

Drag reduction

Viscosity prediction

\begin{abstract}
A B S T R A C T
This paper presents an experimental study on the rheological behavior and viscosity reduction of heavy crude oil and its blends to improve the pipeline transportation by using a Haake RS6000 rheometer and a lab scale flow loop. The apparent viscosity, thixotropic behavior, yield stress and viscoelastic properties were investigated. The results of rheological measurements indicated that with the increase in the diesel volumetric concentration, the viscous modulus and thixotropic behavior of the mixture decreased remarkably; on the contrary, the elastic modulus of heavy crude oil was found to increase slightly. When the start-up rates during the pipe flow were constant, the yield stress decreased exponentially with the increase in temperature. A comparison between rheological measurements and pipe flow data showed that the yield stress measured by the rheometer could be used to predict the start-up yield stress during pipe flow through linear interpolation.

In pipeline flow, the pressure drop was reduced greatly by both heating and dilution with lighter crudes because the viscosity of the heavy crude oil decreased significantly. Drag reduction due to gas injection only occurred at low temperatures or large superficial oil velocities. Moreover, a new viscosity model of heavy crude oil was developed based on the viscosity at $50{ }^{\circ} \mathrm{C}$ to predict the viscosity of heavy crude oil from several oil fields in China. The results reveal that the developed model provided good predictions. Considering that the data contained a wide range of viscosity values, the model suggested in this work is acceptable for practical applications in industry.
\end{abstract}

\section{Introduction}

Heavy crude oil is any type of crude oil that does not flow easily, with lower API values from $10^{\circ}$ to $20^{\circ}$ and high viscosity (Keleşoğlu et al., 2012). Regarding the exploitation of unconventional petroleum resources, heavy crude oil and extra heavy crude oil are attracting extensive attention. However, along with supporting the fast growth of production, how to transport the heavy crude oil in pipelines in an effective and economical way is becoming ever more important. Currently, studies of heavy crude oil in pipeline transportation have primarily focused on viscosity reduction and the rheological properties of crude oil and its blends (Martinez-Palou et al., 2011).

For viscosity reduction, the available methods used to reduce the viscosity of the heavy crude oil mainly include preheating the crude oil, promoting the formation of oil-in-water emulsions, and adding drag reducing agents. Other methods utilized in the pipeline transportation of heavy crude oil emphasize drag reduction by the addition of a second phase. For instance, water-assisted oil-core annular flow, gas/steam injection transportation, and dilution with lighter crudes or alcohols are some of those common methods. Bannwart (2001) provided a so-called oil-core annular flow method to reduce the viscosity since the oil tended to occupy the center of the tube, which was surrounded by a thin annulus of a lubricant fluid (usually water). They found that the corresponding pressure drop was comparable to the flow of water only at the same total volumetric flow rate. Xu et al. $(2007,2009)$ had carried out an experimental and theoretical study of drag reduction by gas injection for power-law fluid flow. A method for predicting the maximum drag reduction ratio was presented. The conclusions revealed that the stronger the shear thinning behavior of the fluids, the more significant the drag reduction was. Ashrafizadeh and Kamran (2010) investigated the stability and viscosity of oil-in-water emulsions and their application for heavy oil pipeline transportation by using two Iranian crude oil samples. Their results showed that the emulsification reduced the viscosity of the crude oil, and the viscosity of the emulsions was increased by increasing

\footnotetext{
* Corresponding author. Institute of Mechanics, Chinese Academy of Sciences, Beijing 100190, China.

E-mail address: xujingyu@imech.ac.cn (J.-y. Xu).
} 
the oil volume content and surfactant concentration. Ghannam et al. (2012) measured the viscosity reduction of heavy crude oil and its mixture with light crude oil. They found that the addition of $10 \%$ light crude oil to the heavy crude oil not only caused strong reduction in the viscosity but also diminished the apparent yield stress completely. Although there are many methods of viscosity reduction, the theoretical models is not well developed. Recently, Centeno et al. (2011) examined the accuracy of seventeen mixing relationships reported in the literature for predicting the apparent viscosity of petroleum and its fractions. They concluded that no rule was capable of estimating the viscosity for all the crude oils, and thus predicting the viscosity of heavy crude oil is still a challenging task.

Another subject that requires further research is the rheological properties of heavy crude oil and its blends. Owing to the different components of saturates, aromatics, resins and asphaltenes, the heavy crude oil can demonstrate more complex rheological properties compared to light crude oil, such as shear-thinning, thixotropy, yield stress and viscoelasticity (Martinez-Palou et al., 2011). Here, the thixotropy reflects memory-dependent properties in which the viscosity of thixotropic fluids undergoes an instantaneous drop to a lower value with increasing length of the shear time (Barnes, 1997). Mortazavi-manesh and Shaw (2014) investigated the thixotropic behavior of Maya crude oil at different temperatures by three kinds of measuring methods, including a hysteresis loop, stepwise change in the shear rate and start-up experiment. Their results showed that the magnitude of the thixotropic characteristics of the crude oil became larger as the temperature decreased, and the relationship between thixotropy and temperature could be expressed by the hysteresis loop area and the stress decay. Yield stress is another important rheological characteristic in the pipeline transportation of heavy crude oil since the fluids cannot be transported when the external force is less than its yield stress. Hasan et al. (2010) investigated the effects of temperature on the yield stress. Their observations indicated that the yield point required to start the flow decreased with the increase in temperature. Meanwhile, the addition of a $10 \%$ volume of light crude oil diminished the yield stress, which meant that the presence of a light crude oil within the heavy crude oil could eliminate the need for any further stresses to be applied. For the viscoelasticity of waxy crude oil and its emulsions, Li et al. (2015) performed an experimental study of the influences of the temperature and water fraction on the elastic modulus, loss modulus, and loss angle. Their studies revealed that by increasing the temperature or reducing the water fraction, the gel structure could be weakened, reflected by a narrower linear viscoelastic region and lower values of the elastic modulus and loss modulus.

The characteristics and behavior of heavy crude oil and its blends should be understood in order to provide a cost-effective solution for pipeliners and refiners (Martinez-Palou et al., 2011; Zhang et al., 2014). However, most of the above studies have been done to evaluate the flow characteristics through rheological instrument measurement, and very little research has been done simultaneously on rheological tests and pipe flow experiments. In practice, the rheological properties from the rheology measurements introduced into the pipe flow conditions is difficult to use to represent the complex flow behavior and physical phenomena (Vielma et al., 2011; Zhang and Xu, 2016). Therefore, to comprehensively understand the flow characteristics of heavy crude oil and its blends from Sui-zhong oilfield and the mechanisms behind it, we start the present study as follows. The first section discusses the measurements of the rheological properties of heavy crude oil and its blends, such as blending the heavy crude oil with lighter oils at different temperatures. The second section includes the investigation of viscosity reduction in pipeline flow, such as preheating the crude oil, drag reduction by gas injection, and dilution with lighter crudes, as well as the investigation of the yield stress during pipeline start-up flow. Finally, a new model was developed to predict the viscosity of heavy crude oil and its blends based on a large group of experimental data collected from this work and those in the literature.

\section{Experimental program}

\subsection{Materials}

The heavy crude oil used in this work came from the Sui-zhong oilfield located in the Bo-hai gulf of China. At a temperature of $30^{\circ} \mathrm{C}$, the crude oil was characterized as having a density of $955 \mathrm{~kg} / \mathrm{m}^{3}$ and a zero-shear viscosity of 5,240 $\mathrm{mPa}$ s. For the dilution, a 0\# diesel from China Petrochem with a density of $845 \mathrm{~kg} / \mathrm{m}^{3}$ at $20^{\circ} \mathrm{C}$ was used as an alternative blending material. Heavy crude oil was blended with the 0 \# diesel in five different volumetric proportions: $0.6 / 5 / 10 / 15 / 25$ vol. $\%$.

\subsection{Rheological measurement}

Rheological measurements were carried out on the Haake RS6000 Rheometer with a coaxial cylinder sensor system (Z38 DIN, gap width $=2.5 \mathrm{~mm}$ and sample volume $=30.8 \mathrm{~cm}^{3}$ ), which has a range of shear rates from $10^{-3} \mathrm{~s}^{-1}$ to $1,000 \mathrm{~s}^{-1}$ and a range of viscosities from $0.001 \mathrm{~Pa} s$ to $1,000 \mathrm{~Pa}$ s. During the oscillatory measurement, an amplitude sweep at a fixed frequency of $1 \mathrm{~Hz}$ was performed prior to the measurement of the frequency sweep in order to ensure the selected stress was maintained in the linear viscoelastic region. In the rheometer, the liquid temperature-controlled units brought the sensor system to a fixed temperature and maintained this temperature throughout the experiment.

During the experiments of the heavy oil blends, the samples were prepared in batches of $500 \mathrm{ml}$ and preheated to a fixed test temperature, and then the samples were homogenized by stirring the heavy crude oil blends for $600 \mathrm{~s}$ using a three-blade stirrer at a fixed speed of $1,000 \mathrm{r} / \mathrm{m}$. After homogenization, the samples were measured by exploiting the performance of the rheometer. The rheological measurements to be discussed include the viscosity profile, thixotropy, yield stress and viscoelastic properties. Moreover, the yield stress was measured by a vane-type rotor FL22 (diameter $=40 \mathrm{~mm}$, four vanes, gap width $=1.5 \mathrm{~mm}$ ), and four shear rates of $0.005 \mathrm{~s}^{-1}, 0.01 \mathrm{~s}^{-1}, 0.05 \mathrm{~s}^{-1}$ and $0.1 \mathrm{~s}^{-1}$ were chosen to investigate the influence of the shear rate on the yield stress.

\subsection{Pipe flow experimental setup and procedure}

To study the start-up yield stress and viscosity reduction of crude oil and its blends, a flow loop with an inner diameter of $47 \mathrm{~mm}$ was made with an absolute roughness of $0.2 \mathrm{~mm}$, and the total length was approximately $15 \mathrm{~m}$, as shown in Fig. 1 . The experimental system was sealed to avoid the evaporation of diesel, and the mixing tank was maintained at three atmospheric pressures. A pressure relief valve was installed at the end of pipeline process so that the system pressure could be maintained at a constant value. Table 1 shows the experimental test matrix for tests carried out in pipe flow. Because of the high viscosity of heavy crude oil, under all conditions the mixture Reynolds number was less than 600 . That was the flow of fluids was located in laminar flow region.

In this system, two pressure transducers, which were made by Rosemount (3051TG) with an accuracy of $\pm 0.75 \%$, were used to measure the pressure fluctuations in the pipe at two different locations. The pressure gradient was measured by a differential pressure transducer, which was made by Rosemount (3051CD) with an accuracy of $\pm 0.75 \%$. In addition, a Coriolis mass flowmeter, Micro Motion F050 from Emerson, was used to monitor the density, temperature and mass flow rate of the heavy crude and its blends.

\subsubsection{Preheating the heavy crude oil}

In this part, the viscosity of the heavy crude oil was changed by adjusting the temperature, which was governed by the heating system in the oil tank. Prior to the experiments, the flow loop was filled with heavy crude oil at a constant temperature. Next, a heat cable wrapped around a 


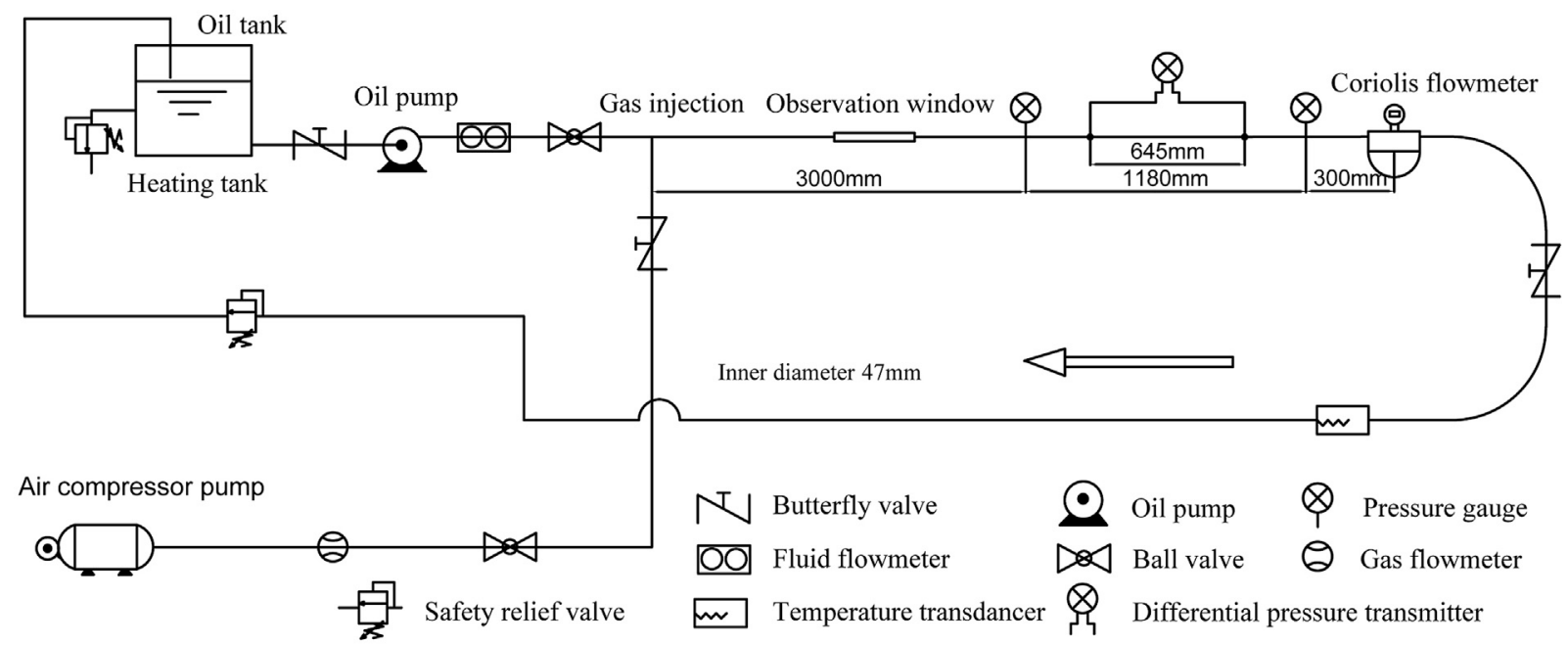

Fig. 1. Schematic view of the flow loop.

Table 1

Experimental test matrix for tests carried out in pipe flow.

\begin{tabular}{|c|c|c|c|c|}
\hline Category & Temperature & Viscosity & Flow rate & Reynolds number \\
\hline Heavy crude oil & $40{ }^{\circ} \mathrm{C} \leq T \leq 70{ }^{\circ} \mathrm{C}$ & $290 \mathrm{mPa} \mathrm{s} \leq \eta_{o} \leq 2410 \mathrm{mPa} \mathrm{s}$ & $2.0 \mathrm{~m}^{3} / \mathrm{h} \leq Q_{o} \leq 10 \mathrm{~m}^{3} / \mathrm{h}$ & $5.9 \leq R e_{o} \leq 246.6$ \\
\hline Heavy crude oil and diesel mixtures & $T=40^{\circ} \mathrm{C}$ & $115 \mathrm{mPa} \mathrm{s} \leq \eta_{o-m i x} \leq 1965 \mathrm{mPa} \mathrm{s}$ & $1.6 \mathrm{~m}^{3} / \mathrm{h} \leq Q_{0 \text {-mix }} \leq 9.6 \mathrm{~m}^{3} / \mathrm{h}$ & $5.8 \leq R e_{o-m i x} \leq 597.3$ \\
\hline Heavy crude oil and air mixtures & $48^{\circ} \mathrm{C} \leq T \leq 68^{\circ} \mathrm{C}$ & $286 \mathrm{mPa} \mathrm{s} \leq \eta_{o-\operatorname{mix}} \leq 1380 \mathrm{mPa} \mathrm{s}$ & $\begin{array}{l}2.0 \mathrm{~m}^{3} / \mathrm{h} \leq Q_{o} \leq 10 \mathrm{~m}^{3} / \mathrm{h} \\
0.0 \mathrm{~m}^{3} / \mathrm{h} \leq Q_{g} \leq 1.5 \mathrm{~m}^{3} / \mathrm{h}\end{array}$ & $10.1 \leq R e_{o-m i x} \leq 215.2$ \\
\hline
\end{tabular}

stainless-steel tube was used to maintain the balance between the frictional heat generation and the pipe wall heat transfer. The pump flow rate was controlled by a frequency converter and measured by a gear flow meter. A large range of viscosities could be obtained from $2.412 \mathrm{~Pa} \cdot \mathrm{s}$ at $40{ }^{\circ} \mathrm{C}$ to $0.292 \mathrm{~Pa} \cdot \mathrm{s}$ at $70{ }^{\circ} \mathrm{C}$. In this instance, the corresponding temperatures were $46^{\circ} \mathrm{C}, 53^{\circ} \mathrm{C}, 58^{\circ} \mathrm{C}, 62^{\circ} \mathrm{C}$ and $67^{\circ} \mathrm{C}$, and the flow rates of the oil phases were $2 \mathrm{~m}^{3} / \mathrm{h}, 4 \mathrm{~m}^{3} / \mathrm{h}, 6 \mathrm{~m}^{3} / \mathrm{h}, 8 \mathrm{~m}^{3} / \mathrm{h}$, and $10 \mathrm{~m}^{3} / \mathrm{h}$, respectively.

\subsubsection{Dilution with the 0\# diesel}

With regard to the dilution, five mixtures with different volumetric concentrations were prepared by adding a certain amount of the $0 \#$ diesel accompanied by gentle stirring to prevent the formation of stratification. The density of each solution was measured using a constant volume density bottle. Furthermore, the rheological behavior of fluids was measured before and after each constant mixture velocity run. The average deviation of the mixture viscosity did not exceed $8.6 \%$, and thus the composition of the mixture was assumed as constant when the concentration was fixed.

\subsubsection{Drag reduction by air injection}

In this part, air came from a compressor, and heavy crude oil was conveyed from the oil tank into the pipeline. Both air and crude oil were fed into the pipeline via a Y-junction. The volumetric flow rates of the two phases could be regulated independently and were measured using a mass flow meter for the air phase and a turbine flow meter for the oil phase. The maximum error of the air flow meter was $\pm 1.5 \%$ of its full scale, and that of the oil flow meter was $\pm 0.5 \%$.

\subsubsection{Start-up flow of heavy crude oil}

During the start-up experiment, the flow loop was filled with heavy crude oil at a constant temperature prior to the tests. Then, the pump was started to force the heavy crude oil to move. At the same time, the flow rate, pressure gradient and temperature were recorded to obtain the corresponding start-up parameters. The sampling frequency was $1,000 \mathrm{~Hz}$, and a total of 300,000 samples were collected, which corresponded to the sampling time of $300 \mathrm{~s}$.

\section{Results and discussion}

\subsection{Rheological property}

\subsubsection{Rheograms}

The rheograms of the heavy crude oil under different temperatures are shown in Fig. 2. It can be seen that at a fixed temperature, the viscosity remained unchanged with the shear rate, especially for those under the conditions of high temperature, which means that the heavy crude oil can be assumed to be a Newton fluid. With the increase in temperature, the viscosity of the heavy crude oil decreased significantly. The oil viscosity decreased from $6.8 \mathrm{~Pa} \cdot \mathrm{s}$ to $0.4 \mathrm{~Pa} \cdot \mathrm{s}$ when the

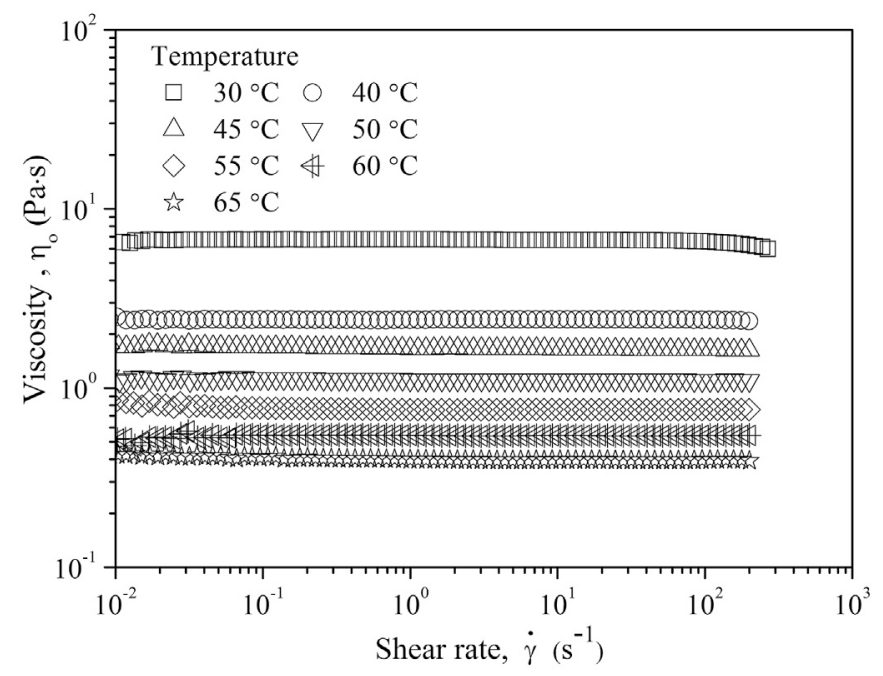

Fig. 2. Rheograms of the heavy crude oil under different temperatures. 


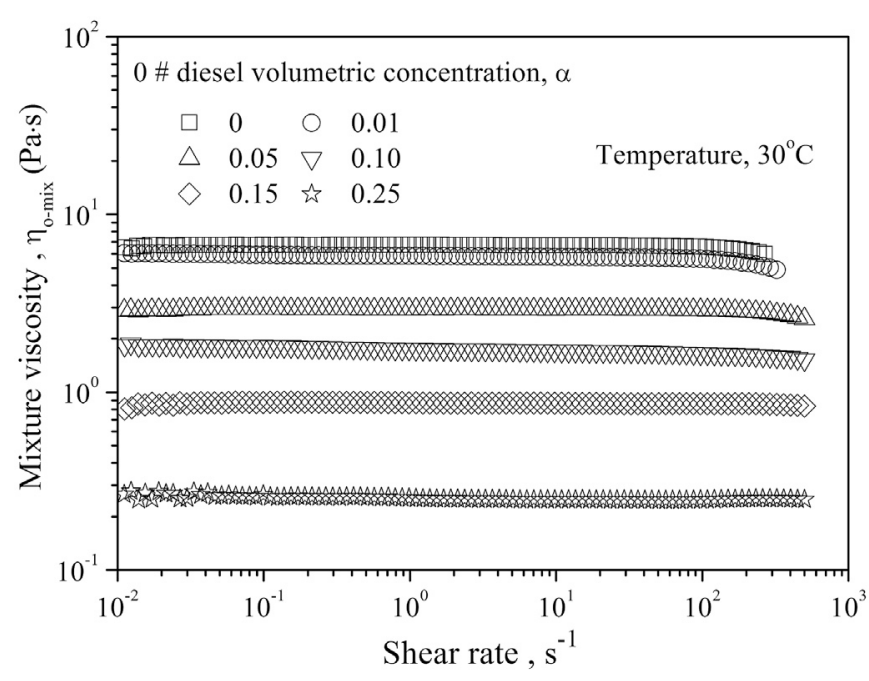

Fig. 3. Rheograms of the heavy crude oil and diesel mixtures with different volumetric concentrations.

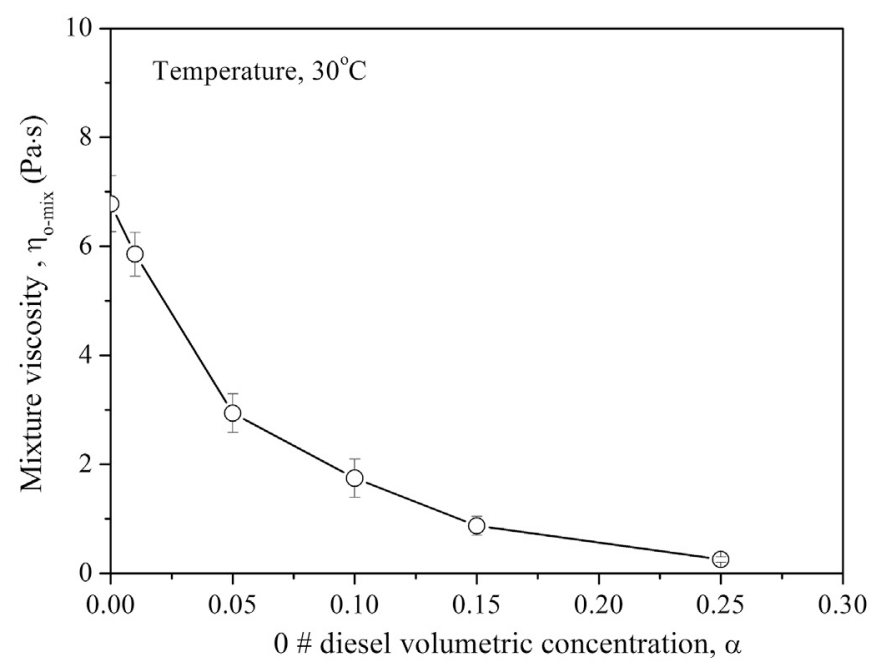

Fig. 4. Mixture viscosity of the heavy crude oil and diesel mixtures against the diesel volumetric concentration.

temperature increased from $30^{\circ} \mathrm{C}$ to $65^{\circ} \mathrm{C}$. Fig. 3 shows the rheograms of the heavy crude oil and the diesel mixtures with different volumetric concentrations. As is shown, the diesel volumetric concentration had a significant impact on the viscosity of the mixture. It is observed in Fig. 4 that the mixture viscosity decreased exponentially with the increasing diesel volumetric concentration. When the diesel volume fraction increased to $10 \%$, the mixture viscosity was reduced from $6.8 \mathrm{~Pa} \mathrm{~s}$ to $1.7 \mathrm{mPa}$ s, namely, a reduction rate of $75 \%$. When the diesel volume fraction further increased to $25 \%$, the reduction rate reached $96 \%$.

\subsubsection{Viscoelastic behavior}

The elasticity of a solid obeys Hooke's law, which means stress is proportional with strain. For viscous liquids, shear stress is proportional to the shear rate, which can be described by Newton's law of viscosity. However, for the heavy crude oil, both viscous and elastic behaviors can be found simultaneously. When alternating loads exist in a pipeline, the viscoelastic behavior of the heavy oil needs to be considered.

Fig. 5 shows the viscoelastic behavior of heavy crude oil at different temperatures, namely, $30^{\circ} \mathrm{C}, 40^{\circ} \mathrm{C}, 60^{\circ} \mathrm{C}$ and $80^{\circ} \mathrm{C}$. It can be seen that with the increase of frequency from $0.1 \mathrm{~Hz}$ to $100 \mathrm{~Hz}$, both the elasticity modulus and the viscous modulus show an increasing trend. Moreover, liquid-like behavior was observed at lower frequencies $\left(\mathrm{G}^{\prime}<\mathrm{G}^{\prime \prime}\right)$, and solid-like behavior was observed at higher frequencies $\left(G^{\prime}>G^{\prime \prime}\right)$. The crossover frequency $\left(G^{\prime}=G^{\prime \prime}\right)$ dependence of the temperature was strong. Namely, the temperature played an important role in the viscoelastic behavior of the heavy crude oil. With the increase in temperature, the viscous modulus decreased remarkably; however, the change of the elasticity modulus was not obvious. Therefore, under the action of a high frequency load, the main consideration should be the elasticity of the heavy crude oil, and in contrast, for a low frequency load, the viscidity of heavy crude oil should be valued. The viscoelastic behavior of the heavy oil and diesel mixtures with different volumetric concentrations at a fixed temperature and frequency is presented in Fig. 6. As is shown, with the increase of the diesel volumetric concentration, the complex viscosity and viscous modulus decreased quickly. In contrast, the elastic modulus increased slowly. This means that the addition of the light petroleum fraction did not significantly change the elastic behavior of the heavy crude oil.

\subsubsection{Yield stress}

During the pipeline transportation of heavy crude oil, the pressure must be large enough so that the crude oil can flow. For the heavy crude oil, a finite elastic deformation occurs when a small external force is exerted. When the external force is large enough, there will be an infinite deformation, and the heavy crude oil flow can be considered as a viscous liquid. In general, the shear stress when the heavy crude oil begins to yield is defined as the yield stress. Therefore, the yield stress and its characteristics should be investigated.

Fig. 7 depicts the yield stress of the heavy crude oil with changing temperatures and shear rates. It is observed that the yield stress decreased exponentially with the increase in temperature at a fixed shear rate of $0.5 \mathrm{~s}^{-1}$. When the temperature was fixed at $30^{\circ} \mathrm{C}$, the yield stress increased linearly with the increase of the shear rate. That is, both the temperature and shear rate played a very large role in the yield stress behavior. Fig. 8 shows the influence of the diesel volumetric concentrations on the yield stress. Here, the diesel volumetric concentration varied within a range from $0 \%$ to $25 \%$. As is shown, similar to the change of the mixture viscosity, the yield stress also exhibited an approximately exponential decline with the increase of the diesel volumetric concentration.

\subsubsection{Thixotropy behavior}

The thixotropy behavior refers to the delayed structure recovery of the heavy crude when the shear force disappears. Fig. 9 displays the thixotropy behavior of the heavy crude oil. The shear rate was first increased from 0 to $300 \mathrm{~s}^{-1}$, and then it decreased to zero. The corresponding shear stress curves constitute the thixotropic loop. The area of the thixotropic loop was used to describe the magnitude of the thixotropy behavior of the heavy crude oil. It can be seen that with the increase in temperature, the area of the thixotropic loop decreased gradually. Because the heavy crude oil forms a relatively strong wax crystal structure at a low temperature, which means has a strong thixotropy so that the hysteresis loop area is large. In other words, at a high temperature, the wax crystal structure is relatively weak so that the hysteresis loop area becomes smaller (Mortazavi-manesh and Shaw, 2014). Additionally, the upward curve was always higher than the downward curve, which means that the structure was damaged faster than its ability to recover.

Fig. 10 shows the area of the thixotropic loop of the heavy crude oil and diesel mixtures against the diesel volumetric concentration. It can be found that similar to the change of the mixture viscosity, the thixotropy behavior decreased exponentially with the increase of the diesel volumetric concentration. Therefore, adding a certain amount of diesel into the heavy crude oil can not only reduce the viscosity but also reduce the thixotropy. 


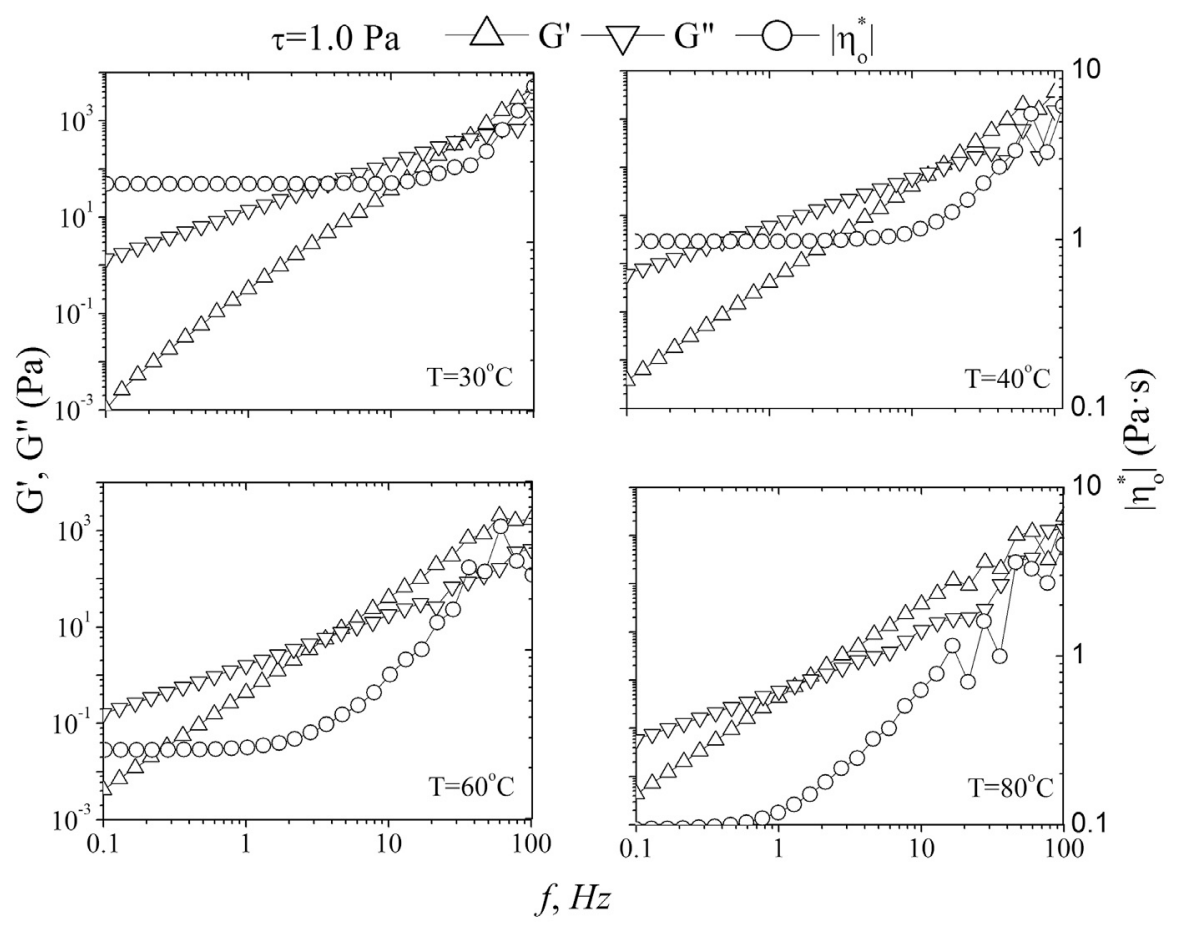

Fig. 5. Viscoelastic behavior of heavy crude oil at different temperatures.

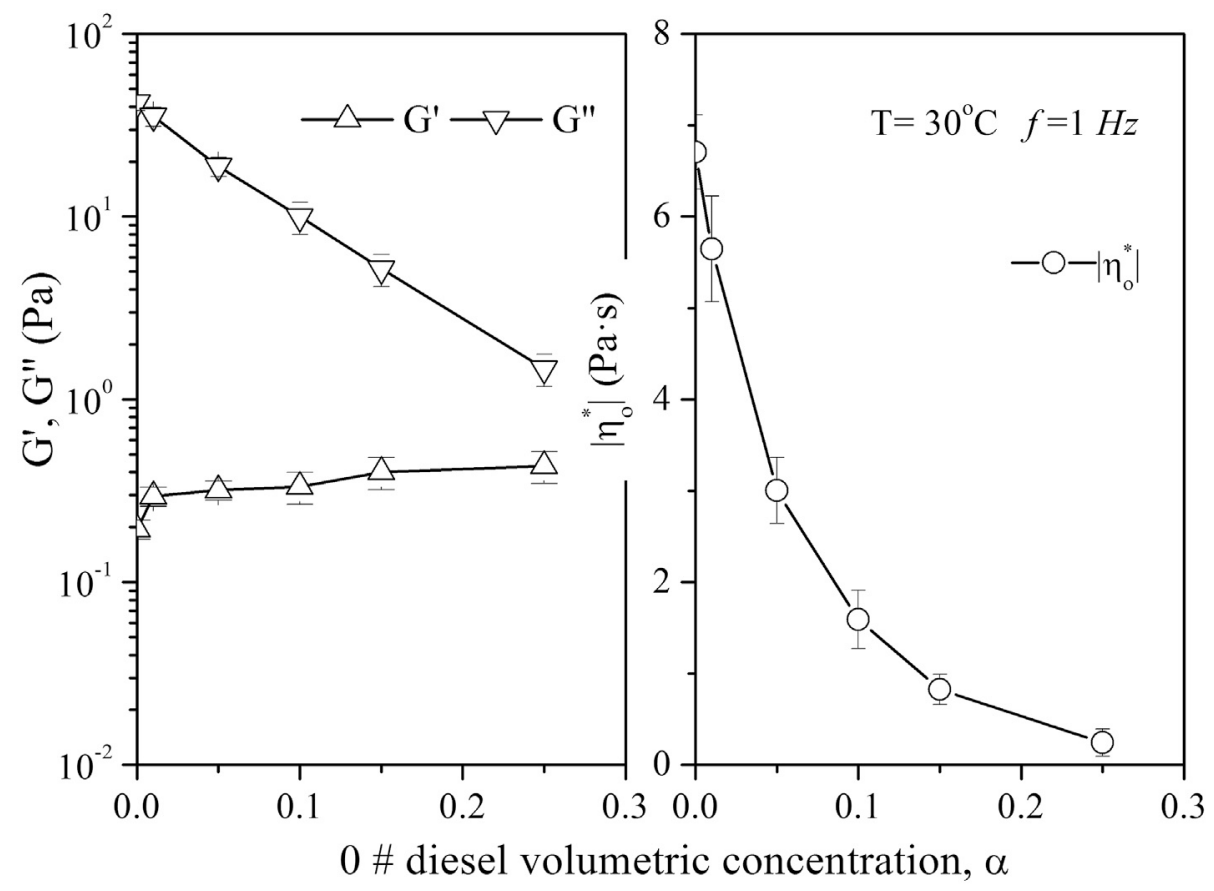

Fig. 6. Viscoelastic behavior of the heavy crude oil and diesel mixtures against the diesel volumetric concentration.

\subsection{Pipe flow characterization}

As previously mentioned, the main purpose of this work was to improve the pipeline transportation of heavy crude oil. Thus, in the following study, the flow characteristics of heavy crude oil and its blends in the pipeline will be introduced. This part is divided into four sections, namely, start-up yield stress, preheating the crude oil, addition of the light petroleum fraction, and drag reduction by gas injection.

\subsubsection{Start-up yield stress}

The shutdown and restart are common problems for heavy crude oil transportation, and the accurate determination of the restart pressure drop is the key to a successful restart. In this section, the heavy oil pipeline was restarted at a fixed flow rate in order to study the restart pressure drop. The measured pressure drop $(\Delta P / L)$ was then converted to the shear stress based on single phase flow characteristics as: 

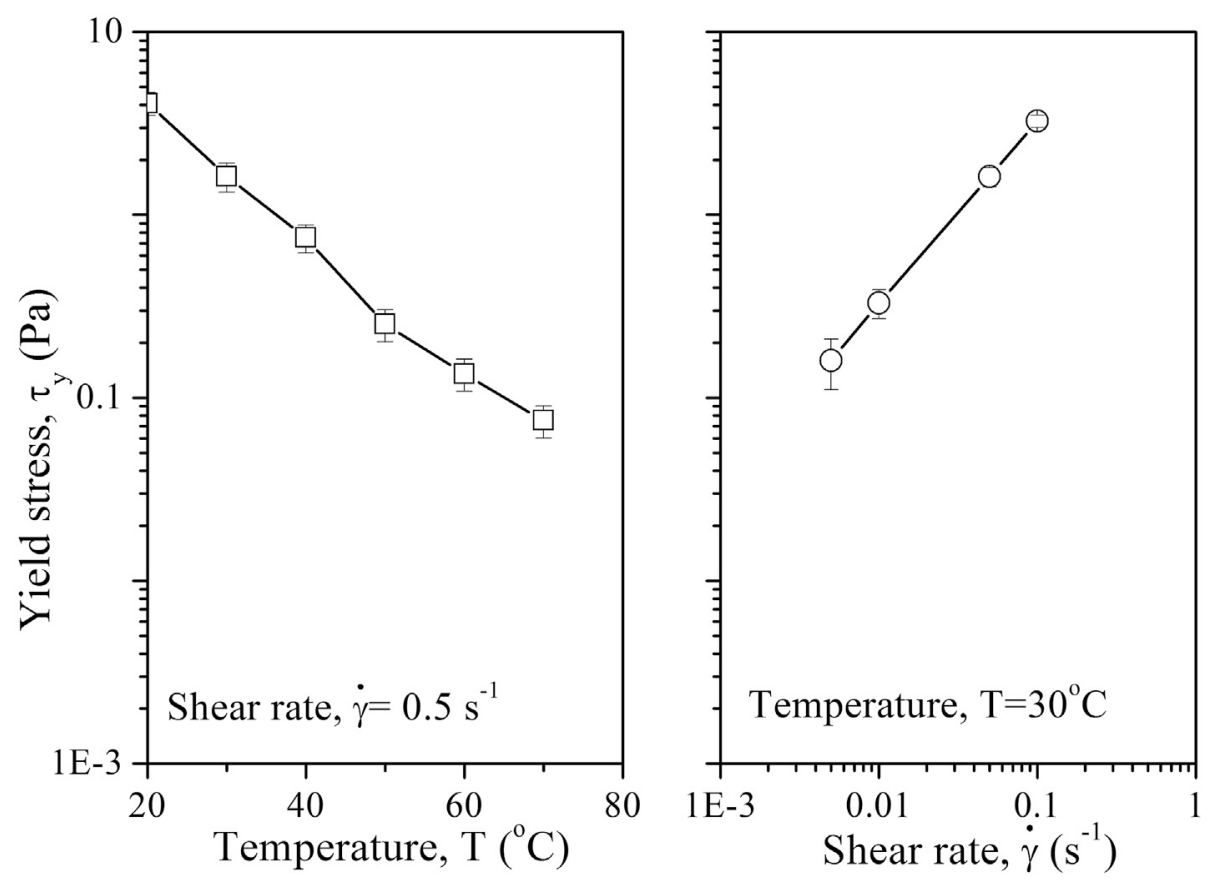

Fig. 7. Yield stress of the heavy crude oil against the temperature and shear rate, respectively.

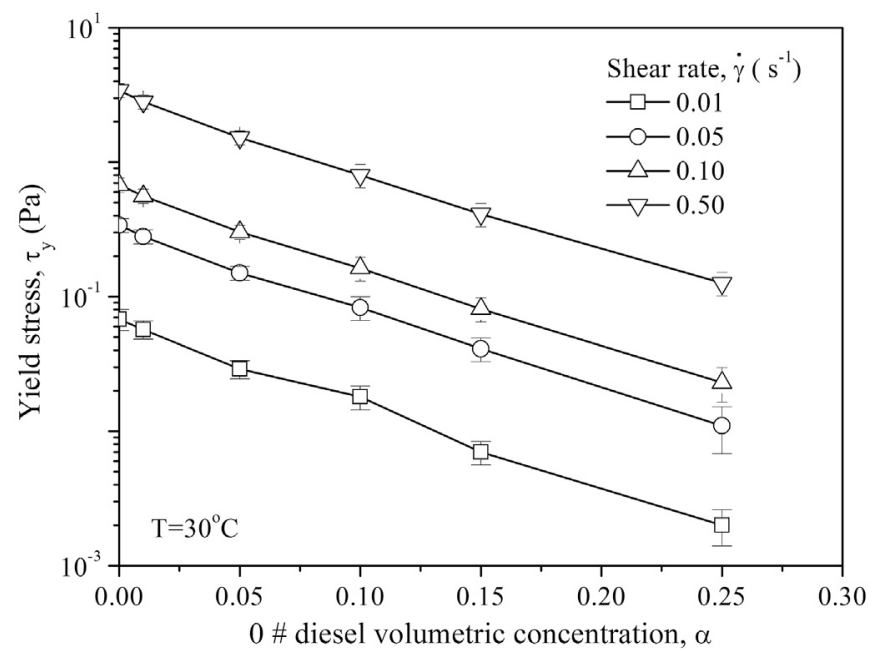

Fig. 8. Yield stress of the heavy crude oil and diesel mixtures against the diesel volumetric concentration.

$\tau_{w}=\frac{D}{4}\left(\frac{\Delta P}{L}\right)$

The corresponding flow rate was converted to the shear rate in laminar flow for a Newtonian fluid as:

$\dot{\gamma}=\frac{32 Q}{\pi D}$

where, $Q$ is the mixture flow rate in $\mathrm{m}^{3} / \mathrm{s}$ and $D$ is the pipe diameter in $m$.

Fig. 11 presents the shear stress changing with time at different shear rates during the restart process. Here, the temperature was $45{ }^{\circ} \mathrm{C}$. The corresponding start-up rates were $40 \mathrm{~s}^{-1}, 70 \mathrm{~s}^{-1}, 134 \mathrm{~s}^{-1}$, and $163 \mathrm{~s}^{-1}$. It can be seen that the restart process can be divided into three stages: the stress rising stage before yield, the stress stable stage during yield, the stress reducing stage after yield. The point with the maximum shear

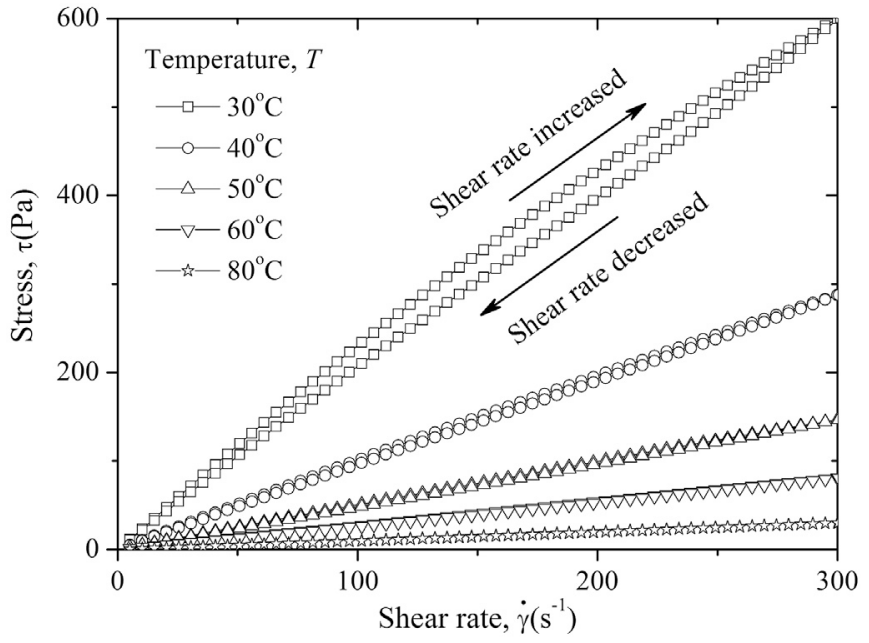

Fig. 9. Thixotropy behavior of the heavy crude oil.

stress during the restart process was defined as the yield point. With the increase of the start-up rate, the yield stress gradually increased. Fig. 12 depicts the influence of the temperature on the yield stress. It was found that when the start-up rates in the pipe flow were fixed, the yield stress decreased exponentially with the increase in temperature. This is similar to the results of the rheological study. To further study the relationship between the rheology and pipe flow, a comparison between the yield stresses measured by the rheometer and those obtained during pipe flow at different temperatures is provided in Fig. 13. Here, the hollow points represent the rheological measurements, and the solid points represent the pipe flow data. It was found that the yield stresses measured by the rheometer are on a straight line with those obtained from the pipe flow. In other words, the yield stresses measured using the rheometer can be used to predict the start-up yield stress in pipe flow through linear interpolation.

\subsubsection{Preheating the crude oil}

The pressure drop of the heavy crude oil changed with the 


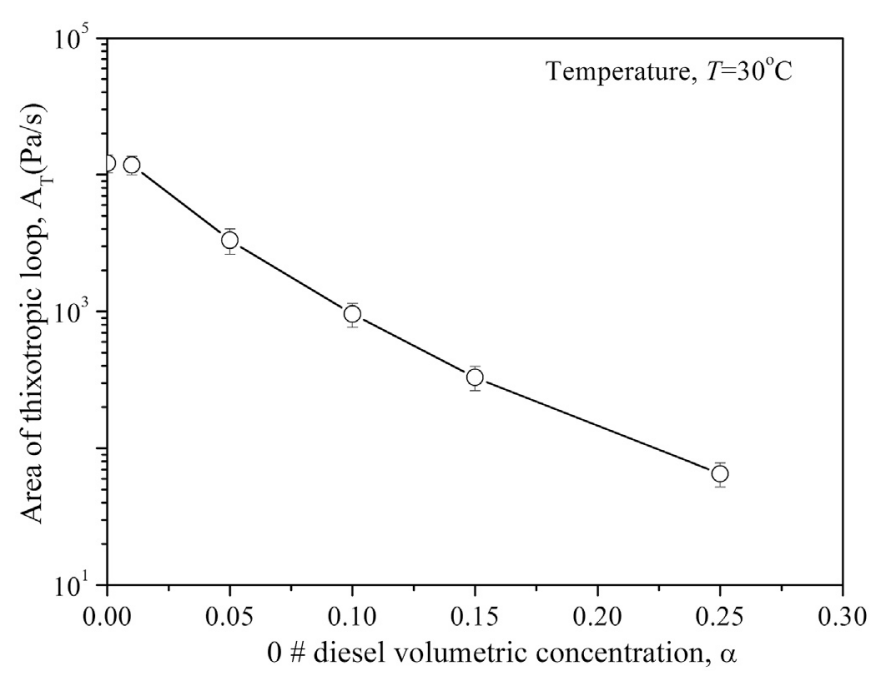

Fig. 10. Area of the thixotropic loop of the heavy crude oil and diesel mixtures against the diesel volumetric concentration.

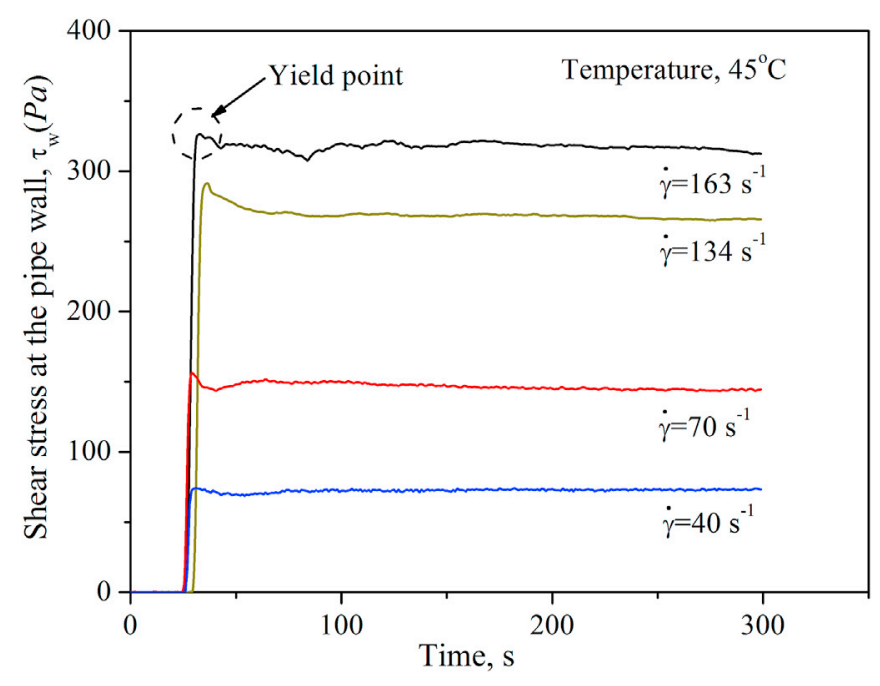

Fig. 11. Shear stress at the pipe wall against time during the process of restarting.

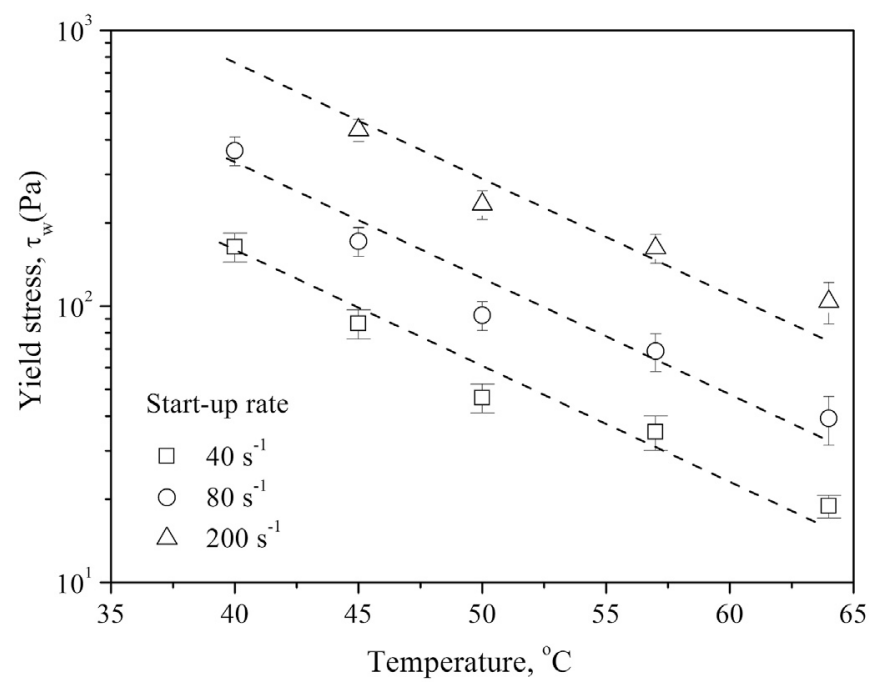

Fig. 12. Yield stress vs. temperature at constant start-up rates for the pipe flow. temperature during single-phase flow was measured. On the basis of the experimental test results, it can be obtained that with the increase in temperature, the pressure drop gradually decreased, and with the increase in the flow rate, the pressure drop curve steeply declined. This is mainly because the viscosity of the heavy crude oil decreased at higher temperatures. Fig. 14 compares the mixture viscosity values obtained in the pipes vs. the temperature with those measured using the rheometer. The solid lines denote the rheograms measured using the rheometer, and the open points represent those obtained from the pipe flow. Here, the viscosities obtained from the pipe flow were back-calculated from experimental data, and the temperatures were $52{ }^{\circ} \mathrm{C}, 58{ }^{\circ} \mathrm{C}, 64^{\circ} \mathrm{C}$ and $67{ }^{\circ} \mathrm{C}$, respectively. In addition, the flow rates in the pipe were $2 \mathrm{~m}^{3} / \mathrm{h}$, $4 \mathrm{~m}^{3} / \mathrm{h}, 6 \mathrm{~m}^{3} / \mathrm{h}, 8 \mathrm{~m}^{3} / \mathrm{h}$ and $10 \mathrm{~m}^{3} / \mathrm{h}$, respectively. It can be noticed from the figure that the data obtained by pipe flow were slightly above those prepared in the rheometer. Specifically, the mixture viscosity exhibited an exponential relationship with the temperature.

\subsubsection{Addition of the diesel fraction}

Addition of a light petroleum fraction is one of the methods used for drag reduction. The diesel volumetric concentration has a significant impact on the mixture viscosity. In this part of the study, the change in the pressure drop with flow rates at different diesel volumetric concentrations during pipe flow was measured. Through the analysis of test data, it can be drawn that with the increase of the flow rate, the pressure drop shows an approximately linear increase. Moreover, at the same flow rate, the increase of the diesel volumetric concentration led to a decrease in the pressure drop. Fig. 15 shows the comparison between viscosities measured by the rheometer and those obtained during pipe flow. Here, the flow rates of the heavy oil and diesel mixture were $1.6 \mathrm{~m}^{3} / \mathrm{h}, 2.6 \mathrm{~m}^{3}$, $\mathrm{h}, 4.8 \mathrm{~m}^{3} / \mathrm{h}, 6 \mathrm{~m}^{3} / \mathrm{h}, 7.2 \mathrm{~m}^{3} / \mathrm{h}$ and $9.6 \mathrm{~m}^{3} / \mathrm{h}$, respectively. Similar to the rheological measurements, with the increase in the diesel volumetric concentration, the mixture viscosity decreased exponentially. At high diesel volumetric concentration, the rheological results are basically consistent with the data from the pipe flow. With the diesel volumetric concentration decreasing, the data measured by pipe flow are higher than those in rheometer. Combined with Fig. 3, this may be due to the fact that at low temperature and high shear rate, the mixtures hold a certain shearthinning property. Therefore, the mixture viscosity obtained by the rheology measurements could be introduced into the accurate calculation of the mixture Reynolds and the friction factor in the pipeline transportation of heavy crude oil and diesel mixture with high volumetric concentration.

\subsubsection{The drag reduction by gas injection}

Gas injection is another method of drag reduction. Some research has demonstrated that adding a small amount of gas into the heavy crude oil can reduce the pressure drop drastically (Xu et al., 2007, 2009). Due to the limitation of experimental conditions, especially for the pump head, in the present study the maximum superficial oil velocity obtained is $1.6 \mathrm{~m} / \mathrm{s}$. In addition, the experiments were carried out at a fixed superficial oil velocity by adjusting the input gas volume fraction from 0.01 to 0.15. Based on previous study (Chen et al., 2016), an average relative error of $0.82 \%$ shows that the measurement results are satisfied for this Coriolis flow meter when the gas fraction is below 15\%. Therefore, in order to meet the measurement requirements, the superficial gas velocity was not to continue to increase at low liquid flow rate.

Fig. 16 depicts the pressure drop against the superficial gas velocity at a fixed superficial oil velocity. Here, the superficial oil velocities were $0.32 \mathrm{~m} / \mathrm{s}, 0.64 \mathrm{~m} / \mathrm{s}, 0.96 \mathrm{~m} / \mathrm{s}, 1.28 \mathrm{~m} / \mathrm{s}$, and $1.6 \mathrm{~m} / \mathrm{s}$. It can be seen in the figure that when the superficial oil velocity was $1.6 \mathrm{~m} / \mathrm{s}$, drag reduction occurred by gas injection. However, when the superficial oil velocity decreased, the effect of gas injection on drag reduction became worse and worse. When the superficial oil velocity was $0.32 \mathrm{~m} / \mathrm{s}$, no drag reduction was found. Fig. 17 presents the change in the pressure drop for superficial velocities at different temperatures. Here, the temperatures were $48^{\circ} \mathrm{C}$, $52{ }^{\circ} \mathrm{C}, 60{ }^{\circ} \mathrm{C}$ and $66^{\circ} \mathrm{C}$, and the superficial oil velocity was $1.60 \mathrm{~m} / \mathrm{s}$. 


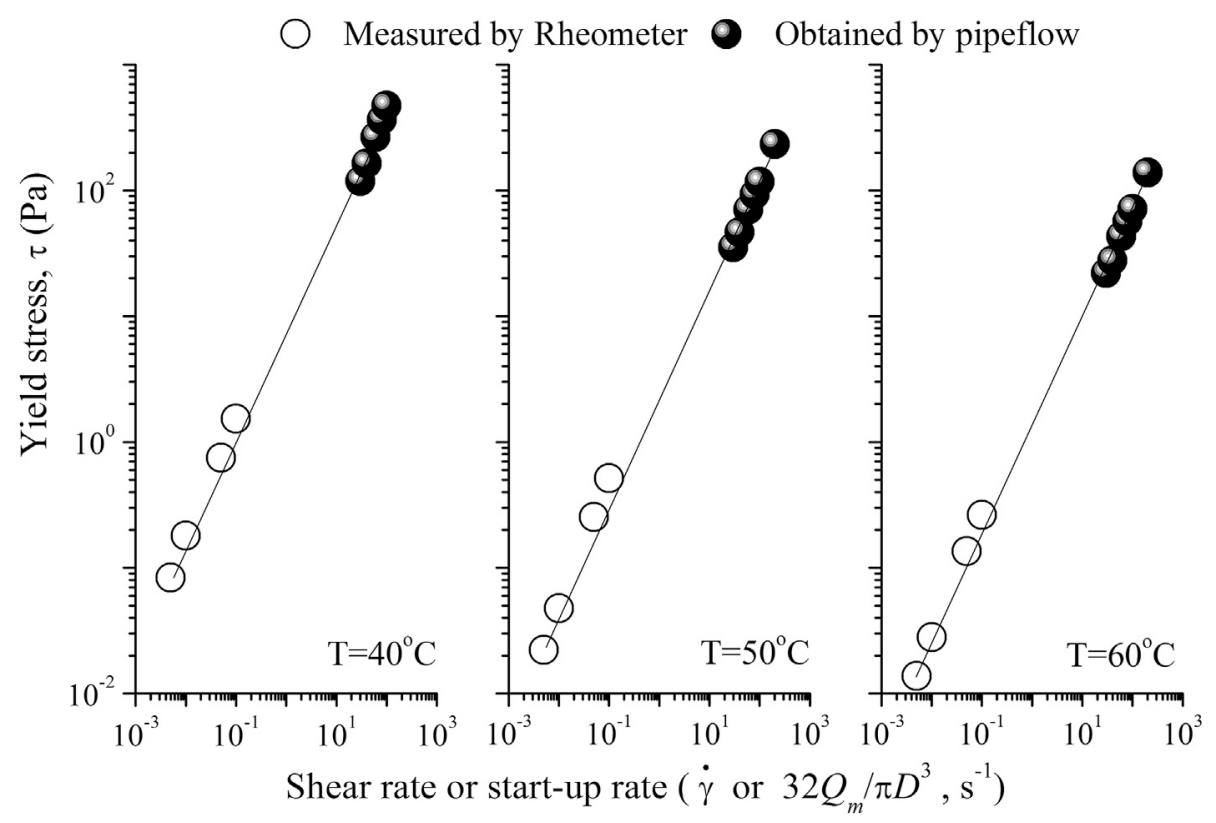

Fig. 13. Comparison between the yield stresses measured by the rheometer and those obtained by pipe flow.

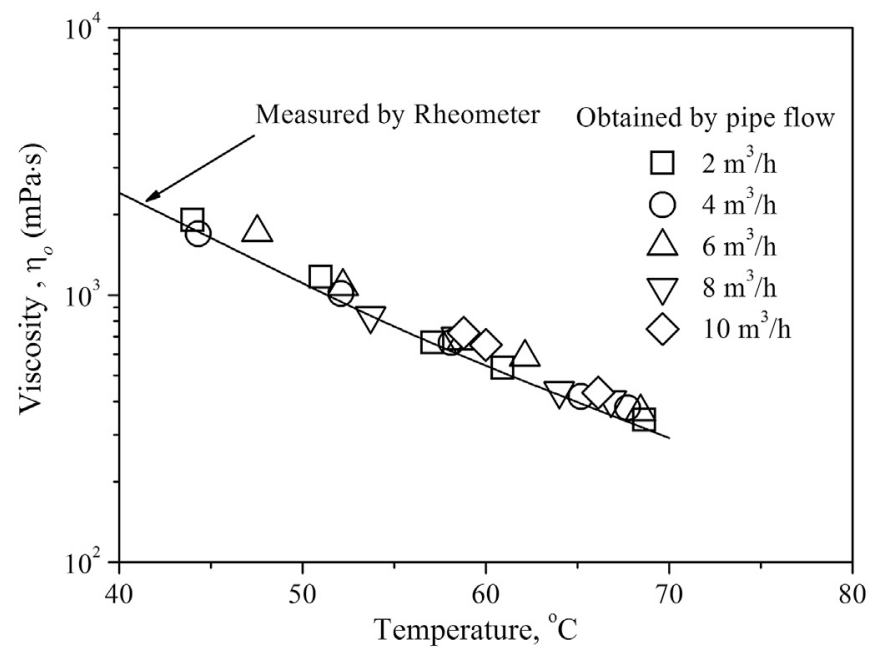

Fig. 14. Comparison between the viscosities measured using the rheometer and those obtained from the pipe flow.

When the temperature was $48{ }^{\circ} \mathrm{C}$, drag reduction occurred. However, with the increase in temperature, the drag reduction disappeared. Moreover, the pressure drop appeared to be independent of the superficial gas velocity. Combined with Fig. 16, it can be concluded that drag reduction occurred only at a low temperature or a large superficial oil velocity. On the one hand, with the increase in the gas flow rate, the mixture viscosity reduction of the two-phase flow will inevitably lead to a decrease in the pressure drop. On the other hand, with the increase in the gas flow rate, the disturbance imposed on the liquid phase by gas will intensify so that the additional pressure loss will increase, which can lead to an increase in the two-phase pressure drop. Therefore, when the gas was added into the pipe flow of the heavy crude oil at a fixed superficial liquid velocity, the two opposing trends would eventually cause the pressure drop of the two-phase flow to increase, decrease, or remain unchanged.

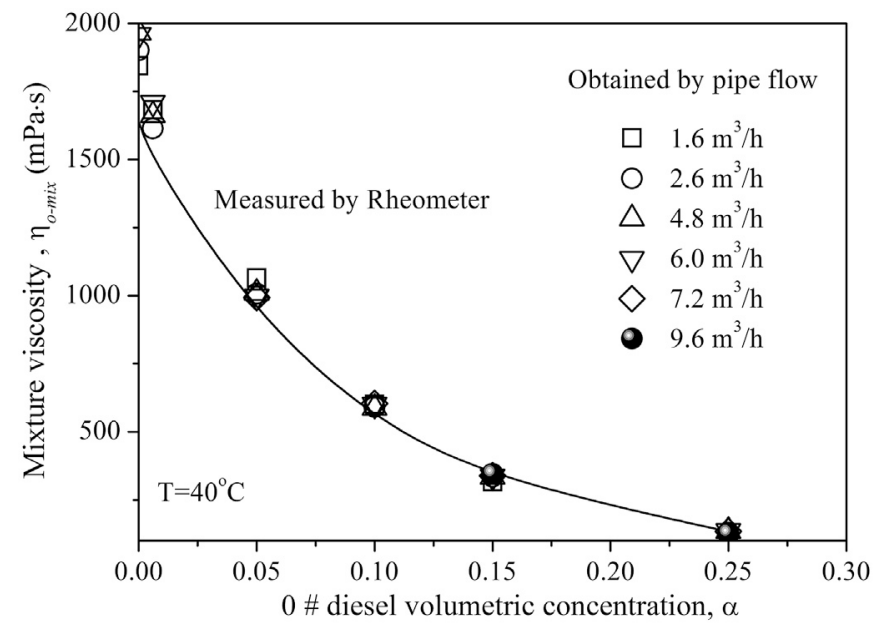

Fig. 15. Comparison between viscosities measured by the rheometer and those obtained during pipe flow.

\subsection{Viscosity prediction}

\subsubsection{Heavy crude oil}

Based on the above experimental data, the existing models for predicting the viscosity of heavy crude oil in the literature were evaluated. Table 2 presents the significant models for predicting the viscosity of heavy crude oil. In general, the models consist of two main parameters, namely, API and system temperature. In the table, $T$ is the Celsius temperature in ${ }^{\circ} \mathrm{C}, T_{f}$ is the Fahrenheit temperature in ${ }^{\circ} \mathrm{F}$ and $\operatorname{Tr}$ is the Rankine temperature in ${ }^{\circ} \mathrm{R}$. Moreover, API refers to the API gravity, which is a measure of how heavy or light a petroleum liquid is compared to water. The formula for calculating API gravity from the specific gravity is (De Ghetto et al., 1995):

$A P I=\frac{141.5}{\rho_{o} / \rho_{w}}-131.5$

where, $\rho$ is the density and the subscripts $o$ and $w$ refer to the heavy crude oil and water, respectively. 


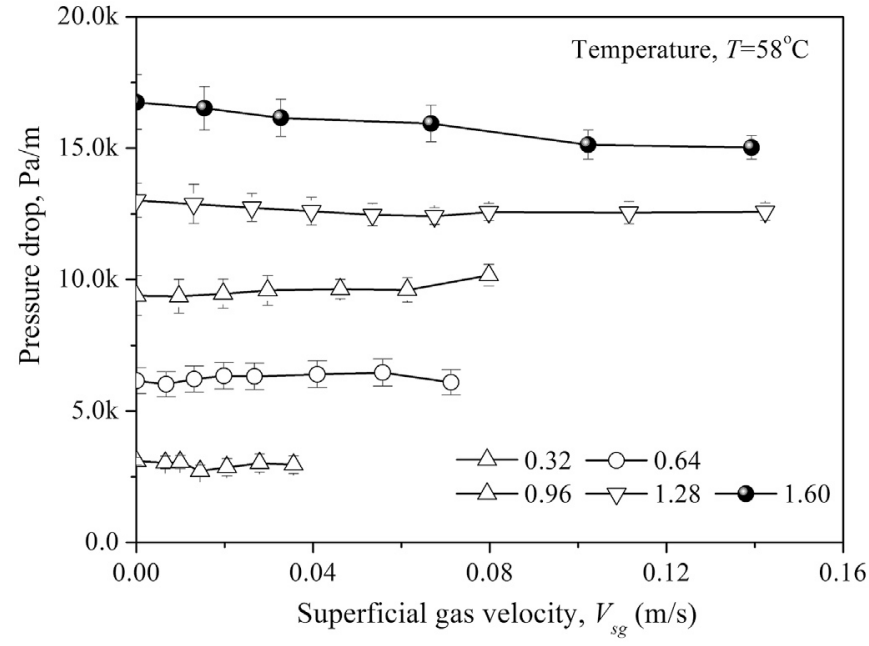

Fig. 16. Pressure drop against the superficial gas velocity at fixed superficial oil velocities.

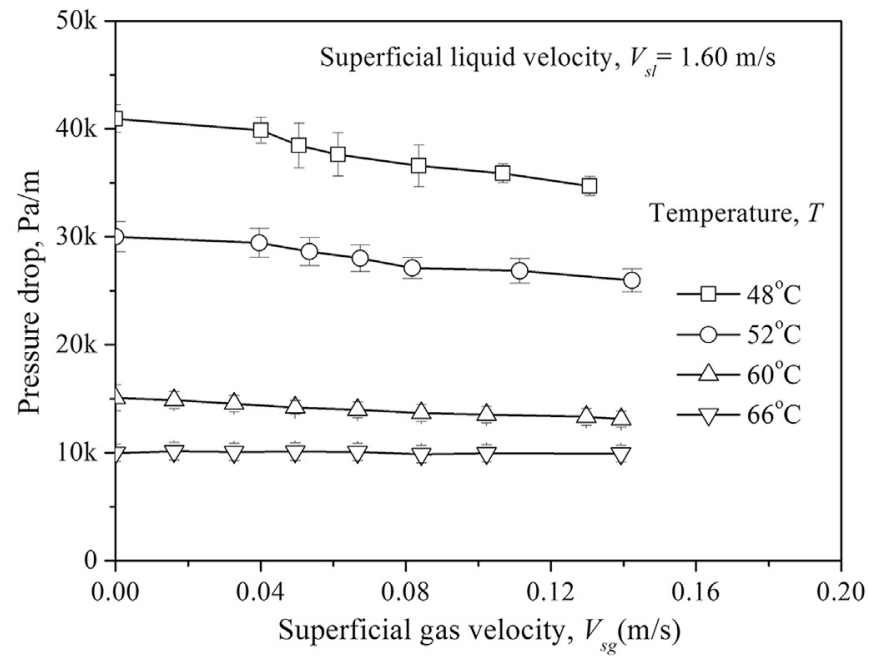

Fig. 17. Pressure drop against the superficial velocities at different temperatures.

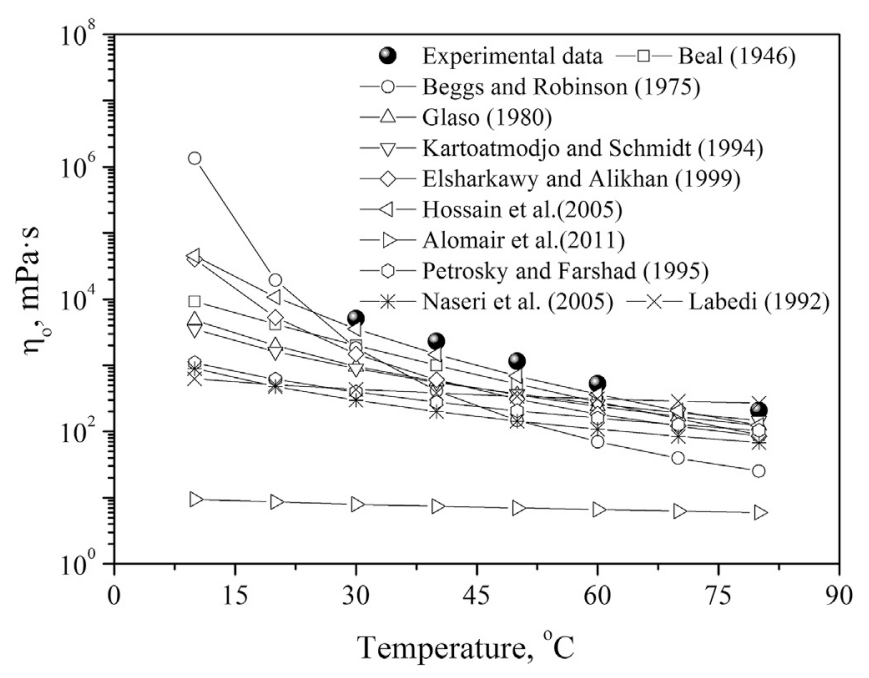

Fig. 18. Comparison between data measured in this work and those predicted by models in the literature.

Fig. 18 shows the comparison between the data measured in this work and those predicted by models in the literature. As can be shown, the results predicted by Hossain et al. (2005) are closer to the measured viscosities. However, the change in viscosity with the temperature is slightly faster than the experimental value. The relationship by Alomair et al. (2014) gives the worst forecasts, and the predicted value is much lower than the actual value. With the increase in temperature, the viscosity predicted by Beggs and Robinson (1975) decreases the most rapidly. In contrast, the prediction curves of Labedi (1992) and Alomair et al. (2014) change slowly with the increasing temperature, which indicates that the temperature is a weak factor in these relationships. Generally, most of the prediction models underestimate the viscosity of heavy crude oil, which indirectly indicates that the Sui-zhong oilfield heavy crude oil components, such as resins and asphaltenes, are present in relatively high amounts so that the viscosity is relatively large. Therefore, a viscosity model capable of predicting the high viscosity from oil fields in China has to be developed.

To develop a new prediction model, a total of 35 sets of viscosity data collected from several different oil fields in China (Zhang et al., 2005; Wang et al., 2015; Kang and Zhang, 2005), consisting of viscosities from $10 \mathrm{mPa}$ s to $10^{7} \mathrm{mPa}$ and their corresponding temperatures from $20^{\circ} \mathrm{C}$

Table 2

Summary of the significant models for predicting the viscosity of heavy crude oil.

\begin{tabular}{|c|c|c|c|c|c|c|}
\hline Authors (Year) & Source of Crude oil & ${ }^{\circ} \mathrm{API}$ & Temperature, ${ }^{\circ} \mathrm{C}$ & Viscosity, mPa s & Models and correlations & $\mathrm{Er}=\% \mathrm{AARD}$ \\
\hline Alomair et al. (2014) & Kuwaiti & $10-20$ & $20-160$ & $1.78-10,000$ & $\eta=30.5149-2.7935 \times \ln \left(T_{f}\right)-1.508 \times[\ln (A P I)]^{2}$ & 97.2 \\
\hline Beal (1946) & U.S. & $10-52$ & 38-104 & $0.8-188$ & $\eta=\left(0.32+\frac{1.8 \times 10^{7}}{A P^{4.53}}\right)\left(\frac{360}{T_{r}-260}\right)^{a} ; a=10^{(0.43+8.33 / A P I)}$ & 47.4 \\
\hline Beggs and Robinson (1975) & N/A & $16-58$ & $21-146$ & N/A & $\begin{array}{l}\eta=10^{x}-1 ; x=y \times\left(T_{r}-460\right)^{-1.163} \\
y=10^{z} ; z=3.0324-0.02023 \times A P I\end{array}$ & 78.7 \\
\hline Elsharkawy and Alikhan (1999) & Middle east & $20-48$ & $38-149$ & $0.6-33.7$ & $\begin{array}{l}\eta=\text { anti } \log _{10}(x)-1 ; x=\text { anti } \log _{10}(y) \\
y=2.16924-0.02525 \times A P I-0.68875 \times \log _{10}\left(T_{f}\right)\end{array}$ & 47.0 \\
\hline Glaso (1980) & North Sea & $20-48$ & $10-149$ & $0.6-39$ & $\begin{array}{l}\eta=\left(3.141 \times 10^{10}\right) \times\left(T_{r}-460\right)^{-3.444} \times\left[\log _{10}(A P I)\right]^{a} \\
a=10.313 \times\left[\log _{10}\left(T_{r}-460\right)\right]-36.447\end{array}$ & 57.1 \\
\hline Hossain et al. (2005) & Data Bank & $15.8-22.3$ & $51-93$ & $3-517$ & $\eta=10^{(-0.71523 \times A P I+22.13766)} T_{f}^{(0.269024 \times A P I-8.268047)}$ & 28.7 \\
\hline Kartoatmodjo and Schmidt (1994) & Data Bank & $14.4-59$ & $27-160$ & $0.5-586$ & $\begin{array}{l}\eta=16 \times 10^{8} \times T_{f}^{-2.8177} \times\left(\log _{10} A P I\right)^{x} \\
x=5.7526 \times \log _{10}\left(T_{f}\right)-26.9718\end{array}$ & 55.7 \\
\hline Labedi (1992) & Africa & $32-48$ & $38-152$ & $0.6-4.8$ & $\eta=\frac{10^{9.224}}{A P 1^{4.7013} \times T_{f}^{0.6739}}$ & 54.4 \\
\hline Naseri et al. (2005) & Iran & $17-44$ & $41-146$ & $0.75-54$ & $\begin{array}{l}\eta=\text { anti } \log _{10}(y) \\
y=11.2699-4.298 \times \log _{10}(A P I)-2.052 \times \log _{10}\left(T_{f}\right)\end{array}$ & 76.2 \\
\hline Petrosky and Farshad (1995) & Mexico & $25.4-46.1$ & $46-142$ & $0.725-10.249$ & $\begin{array}{l}\eta=2.3511 \times 10^{7} \times T_{f}^{-2.10255}\left[\log _{10}(A P I)\right]^{x} \\
x=4.59388 \times \log _{10}\left(T_{f}\right)-22.82792\end{array}$ & 70.3 \\
\hline
\end{tabular}


Table 3

Viscosity data used from oil fields in China for developing the model.

\begin{tabular}{|c|c|c|c|c|c|}
\hline Author & Source of heavy crude oil & Temperature, ${ }^{\circ} \mathrm{C}$ & Viscosity at $50{ }^{\circ} \mathrm{C}, \eta_{50}\left(\mathrm{mPa}^{\circ} \mathrm{s}\right)$ & Types of heavy oil & Data points \\
\hline Wang et al. (2015) & Bo-hai oilfield & $20-90$ & $366.4-72,477$ & 5 & 32 \\
\hline Zhang et al. (2005) & Liao-he oilfield & $40-90$ & $76-34,590$ & 20 & 100 \\
\hline Kang and Zhang, 2005 & Liao-he oilfield & $20-90$ & $209-216,230$ & 7 & 49 \\
\hline In this work & Sui-zhong oilfield & $20-90$ & $77-1,147$ & 3 & 21 \\
\hline
\end{tabular}

to $90{ }^{\circ} \mathrm{C}$, are summarized in Table 3 . First, the relationship between viscosity and temperature was analyzed, and yet no uniform rules were found. That is, even at the same temperature, the viscosity of the heavy crude oil varies widely. Therefore, the temperature is not the only factor affecting the viscosities of the different heavy crude oils (Cruz et al., 2013). Based on the experimental observations, the viscosity at $50{ }^{\circ} \mathrm{C}$ $\left(\eta_{50}\right)$ was used as the other factor since $\eta_{50}$ provides an indication of the particular type of heavy crude oil (Zhang et al., 2005).

Fig. 19 shows the viscosity change in the heavy crude oil with $\eta_{50}$. Here, the temperatures were $20^{\circ} \mathrm{C}, 30^{\circ} \mathrm{C}, 40^{\circ} \mathrm{C}, 60^{\circ} \mathrm{C}, 70^{\circ} \mathrm{C}, 80^{\circ} \mathrm{C}$ and $90^{\circ} \mathrm{C}$, respectively. It can be found that all curves demonstrated a similar regularity. That is, when the temperature was constant, the viscosity of the heavy crude oil gradually increased with $\eta_{50}$. This is mainly because $\eta_{50}$ can be considered as a benchmark for identifying the type of heavy crude oil. For the same temperature, the greater the $\eta_{50}$, the thicker the crude oil and the greater the viscosity is. Therefore, based on existing research results (Zhang et al., 2005), a power-law relationship was adopted to analyze the data sets in Mathematica software. The relationship between the viscosity and $\eta_{50}$ was re-extracted from the experimental data as:

$\eta_{o}=c \eta_{50}{ }^{n}$

where, $c$ and $n$ are two parameters. A good fitting result was obtained $\left(R^{2}>0.98\right)$, revealing that there is a certain degree of similarity between the characteristics of heavy crude oil in China.

Fig. 20 shows the variation of two parameters with the dimensionless temperature, which is defined as the ratio of the temperature and $50{ }^{\circ} \mathrm{C}$. As seen from the figure, with the increase in temperature, parameter $c$ increased and parameter $n$ decreased. Thus, the two parameters were fitted with Equations (5) and (6), respectively, as:

$c=a_{1} b_{1}^{\log _{10} \bar{T}}$

$n=a_{2} \log _{10} \bar{T}+b_{2}$

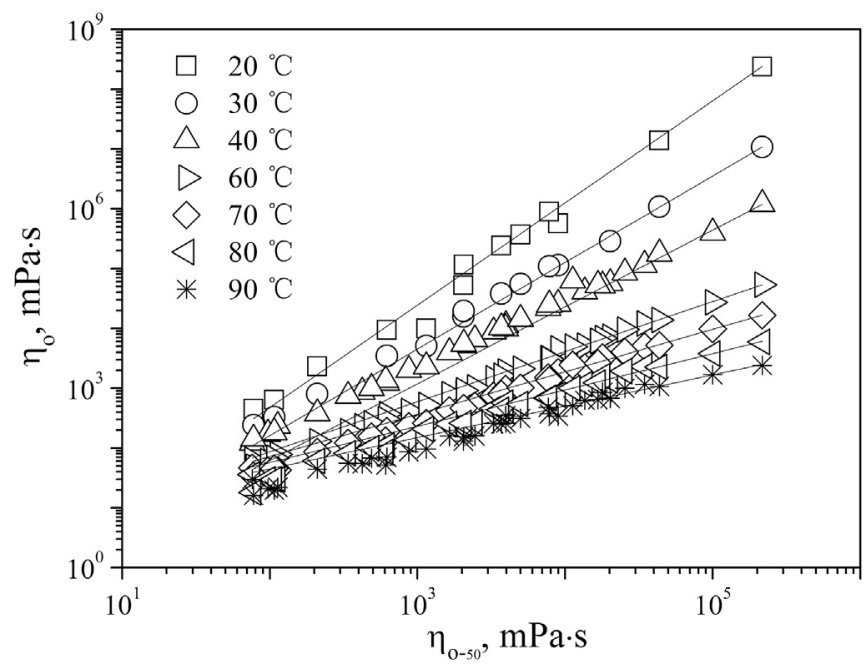

Fig. 19. Viscosity change in the heavy crude oil with the viscosity at $50{ }^{\circ} \mathrm{C}$.

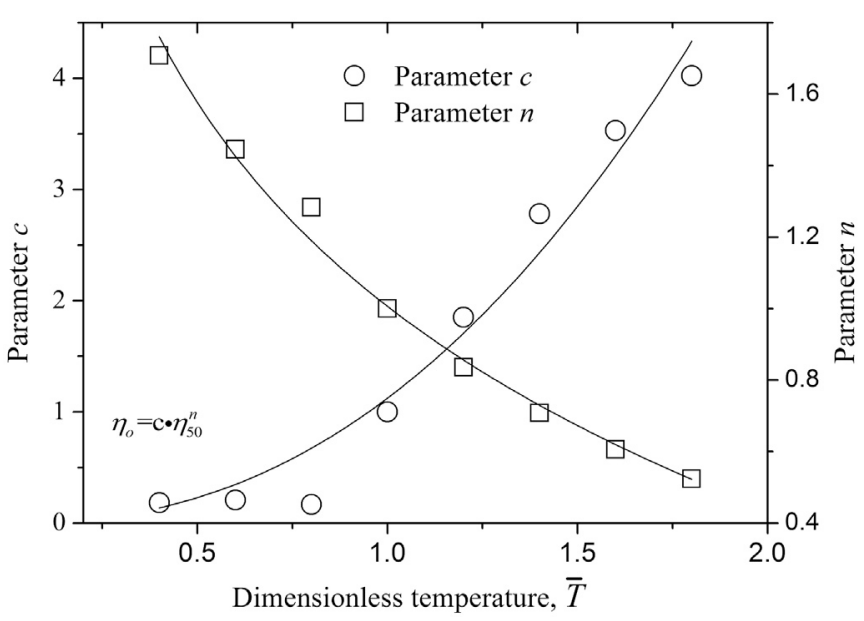

Fig. 20. Variation of the two parameters in Equation (4) with the dimensionless temperature.

where, the values of the four empirical coefficients, $a_{1}=1.123$, $a_{2}=-0.823, b_{1}=9.926$, and $b_{2}=1.006$, were obtained by a regression analysis. Good agreement was observed between the experimental data and the predicted results, namely, $R^{2}=0.96$ for $c$ and $R^{2}=0.99$ for $n$.

In the present study, the average absolute relative deviations (\% $A A R D$ ) was used to evaluate the accuracy of the model generated here and compare it with other literature models:

$E r=\% A A R D=\frac{1}{n} \sum_{i=1}^{n} \frac{\left|\eta_{c a l}-\eta_{\exp }\right|}{\eta_{\exp }} \times 100$

where, $\eta_{c a l}$ is the viscosity calculated by the developed model and those in literature, respectively. $\eta_{\text {exp. }}$ is the viscosity measured through experiments. The number of experimental points used was approximately 202. Analytical results for the models in literature are shown in Table 2. It can be seen that for all types of heavy crude oil in China, the prediction errors range from 28.7 to 97.2 , which is relatively large. The comparison between the experimental and predicted viscosities by the model suggested in this work is shown in Fig. 21. It can be found that the developed correlation can describe the majority of the experimental data within $\pm 20 \%$, and the average absolute relative deviations $(E r=\% A A R D)$ is 13.7, which is better than the other models. Considering that the data contains a wide range of viscosities, the relationship suggested in this work is acceptable for practical applications in industry.

\subsubsection{Heavy crude oil and diesel mixtures}

As is shown in Figs. 4 and 14, the mixture viscosity of the heavy crude oil and diesel decreased exponentially with the increase of the diesel volumetric concentration. Therefore, an index equation was assumed to describe the relationship between the mixture viscosity and the diesel volumetric concentration as follows:

$\eta_{o-m i x}=a_{3} e^{b_{3} \alpha}$

where $\alpha$ represents the diesel volumetric concentration, and $a_{3}$ and $b_{3}$ are parameters. When $\alpha=0, \eta_{o-m i x}=\eta_{o}=a_{3}$; when $\alpha=1, \eta_{o-m i x}=\eta_{l}$. That is, 


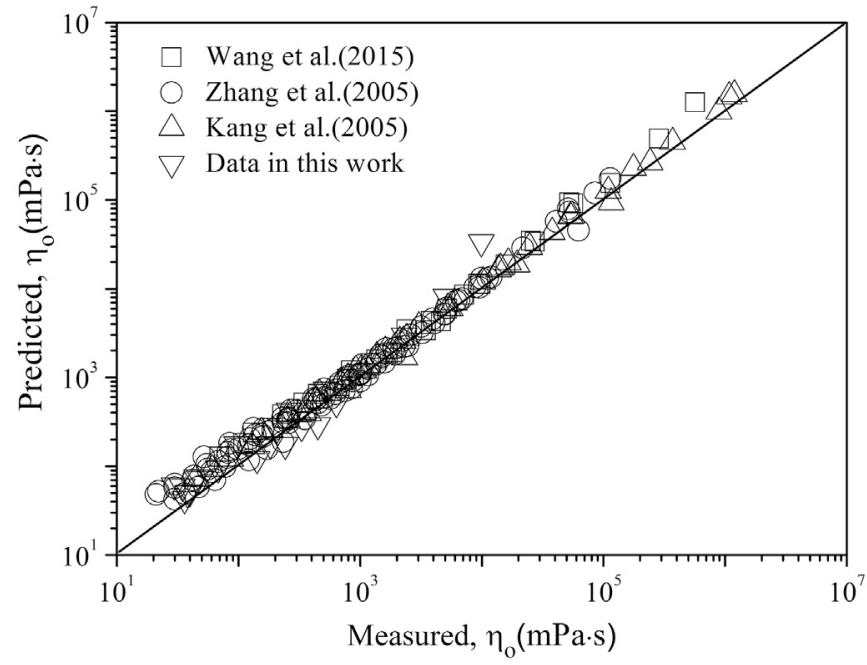

Fig. 21. Comparison between the experimental and predicted viscosities of the heavy crude oil.

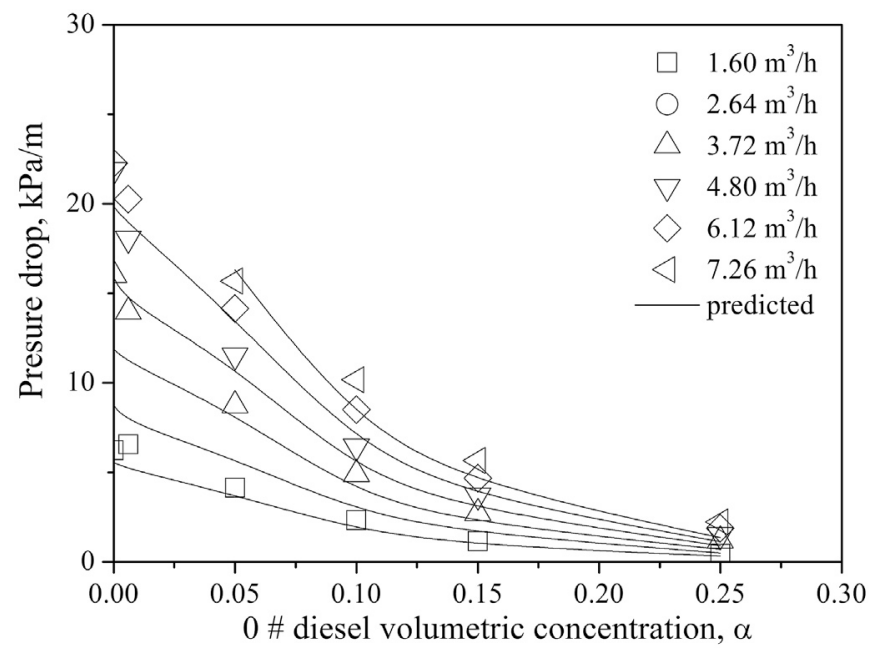

Fig. 22. Comparison between the predicted and measured pressure drops during pipe flow.

$\operatorname{In}\left(\eta_{l} / \eta_{o}\right)=b_{3}$. In the formula, $\eta_{o}$ and $\eta_{l}$ represent the heavy crude oil viscosity and the diesel viscosity, respectively. Thus, Equation (8) can be rewritten as:

$\eta_{o-\operatorname{mix}}=\eta_{o}\left(\frac{\eta_{l}}{\eta_{o}}\right)^{\alpha}$

where $\eta_{o}$ can be obtained by Equation (4). Once the viscosity and volumetric concentration of the diesel are known, the above formula can be used to predict the mixture viscosity.

Fig. 22 shows the comparison between the predicted and measured pressure drops during pipe flow after using Equation (8) to calculate the mixture viscosity. Here, the solid line represents the calculated pressure drops, and the data points represent the pressure drops measured during pipe flow. It can be seen that the accuracy of the theoretically predicted results was very high, and the pressure drop decreased exponentially with the increase of the diesel volumetric concentration. In general, the addition of dilute oil is a good method for drag reduction.

\section{Conclusion}

In this work, rheological measurements and pipe flow experiments using Sui-zhong heavy crude oil from China and its blends were carried out by using a Haake RS6000 rheometer and a lab scale flow loop to improve the pipeline transportation.

The rheology measurements indicated that when heavy oil bears an alternating load, the viscoelastic behavior needs to be considered. With the increase in the diesel volumetric concentration, the viscous modulus and the thixotropy behavior are reduced remarkably; on the contrary, the elastic modulus of heavy crude oil was found to increase slightly. When the start-up rates during pipe flow were constant, the yield stress decreased exponentially with the increase in temperature. In addition, the yield stress measured by the rheometer could be used to predict the start-up yield stress during pipe flow through linear interpolation.

The pressure drop in the pipeline could be reduced greatly by heating since the viscosity of the heavy crude oil decreased significantly with the increase in temperature. The diesel volumetric concentration had a significant impact on the mixture viscosity. With the increase in the diesel volumetric concentration, the mixture viscosity decreased exponentially. Moreover, drag reduction by gas injection only occurred at a low temperature or a large superficial oil velocity.

Viscosity prediction models for crude oil and diesel mixtures was developed based on experimental data collected from several different oil fields in China. The results revealed that the developed models achieved accurate predictions. Considering that the data contains a wide range of viscosities, the relationship suggested in this work is acceptable for practical applications in industry.

\section{Acknowledgements}

This study is supported by the Strategic Priority Research Program of the Chinese Academy of Science (Grant No. XDB22030101) and the National Natural Science Foundation of China (Grant No. 51509235).

\section{References}

Alomair, O., Elsharkawy, A., Alkandari, H., 2014. A viscosity prediction model for Kuwaiti heavy crude oils at elevated temperatures. J. Pet. Sci. Eng. 120, 102-110.

Ashrafizadeh, S.N., Kamran, M., 2010. Emulsification of heavy crude oil in water for pipeline transportation. J. Pet. Sci. Eng. 71, 205-211.

Bannwart, A.C., 2001. Modeling aspects of oil-water core-annular flows. J. Pet. Sci. Eng. $32,127-143$.

Barnes, H.A., 1997. Thixotropy-a review. J. Newt. Fluid Mech. 70, 1-33.

Beal, C., 1946. The viscosity of air, water, natural gas, crude oil and its associated gases at oil field temperature and pressures. Trans. AIME 165 (1), 94-115.

Beggs, H.D., Robinson, J.R., 1975. Estimating the viscosity of crude oil systems. J. Pet, Tech. 27, 1140-1141.

Centeno, G., Sánchez-Reyna, G., Ancheyta, J., Muñoz, J.A.D., Cardona, N., 2011. Testing various mixing rules for calculation of viscosity of petroleum blends. Fuel 90, 3561-3570.

Chen, X.P., Xu, J.Y., Zhang, J., 2016. A simple model for predicting the two-phase heavy crude oil horizontal flow with low gas fraction. Chem. Eng. Comm. 203, 1131-1138.

Cruz, J.L.M., Alvarez-Badillo, S., Ramírez-Jaramillo, E., Aquino-Olivos, M.A., Orea, P., 2013. Measurements and correlation of Mexican heavy dead crude oil viscosities. J. Pet. Sci. Eng. 110, 184-192.

De Ghetto, G., Paone, F., Villa, M., 1995. Pressure volume-temperature correlation for heavy and extra heavy oils. SPE 30316, Presented at SPE Conference, Calgary, Alberta, Canada, June.

Elsharkawy, A.M., Alikhan, A.A., 1999. Models for predicting the viscosity of Middle East crude oils. Fuel 78, 891-903.

Ghannam, M.T., Hasan, S.W., Abu-Jdayil, B., Esmail, N., 2012. Rheological properties of heavy \& light crude oil mixtures for improving flowability. J. Pet. Sci. Eng. 81, $122-128$.

Glaso, O., 1980. Generalized pressure-volume-temperature correlation for crude oil system. J. Pet. Tech. 2, 785-795.

Hasan, S.W., Ghannam, M.T., Esmail, N., 2010. Heavy crude oil viscosity reduction and rheology for pipeline transportation. Fuel 89, 1095-1100.

Hossain, M.S., Sarica, C., Zhang, H.Q., Rhyne, L., Greenhill, K.L., 2005. Assessment and development of heavy oil viscosity correlations. In: SPE International Thermal Operations and Heavy Oil Symposium, Calgary, Alberta, Canada, November 1-3. Paper SPE 97907.

Kang, Z.Y., Zhang, Y., 2005. Calculation of heavy oil viscosity general equation of Liao-he oil region. J. Spec. Reserv. 12 (6), 101-102 (In Chinese).

Kartoatmodjo, T., Schmidt, Z., 1994. Large data bank improves crude physical property correlations. Oil Gas J. 92 (27), 51-55.

Keleșoğlu, S., Pettersen, B.H., Sjöblom, J., 2012. Flow properties of water-in-North Sea heavy crude oil emulsions. J. Pet. Sci. Eng. 100 (4), 14-23. 
Labedi, R., 1992. Improved correlations for predicting the viscosity of light crudes. J. Pet. Sci. Eng. 8, 221-234.

Li, H.Y., Zhang, J.J., Song, C.F., Sun, G.Y., 2015. The influence of the heating temperature on the yield stress and pour point of waxy crude oils. J. Pet. Sci. Eng. 135, 476-483.

Martinez-Palou, R., Mosqueira, M.L., Zapata-Rendon, B., Mar-Juarez, E., BernalHuicochea, C., Clavel-Lopez, J.C., Aburto, J., 2011. Transportation of heavy and extra-heavy crude oil by pipeline: a review. J. Pet. Sci. Eng. 75, 274-282.

Mortazavi-manesh, S., Shaw, J.M., 2014. Thixotropic rheological behavior of Maya crude oil. Energy Fuel. 28 (2), 972-979.

Naseri, A., Nikazar, M., Dehghani, S.A., 2005. A correlation approach for prediction of crude oil viscosities. J. Pet. Sci. Eng. 47, 163-174.

Petrosky Jr., G.E., Farshad, F.F., 1995. Viscosity correlation for Gulf of Mexico crude oil. In: SPE Production Operations Symposium, Oklahoma, OK, April 2-4. SPE Paper 29468.

Vielma, J.C., Shoham, O., Mohan, R.S., Gomez, L.E., 2011. Prediction of frictional pressure gradient in horizontal oil/water dispersion flow. SEP J. 148-154. SPE 139406, March.
Wang, D.W., Yue, B.L., Liu, X.H., Zhang, F.Y., 2015. The study of viscosity-temperature relationship of bohai heavy oil reservoir. J. Pet. Geol. Eng. 29 (5), 84-86 (In Chinese).

Xu, J.Y., Wu, Y.X., Li, H., Guo, J., Chang, Y., 2009. Study of drag reduction by gas injection for power-law fluid flow in horizontal stratified and slug flow regimes. Chem. Eng. J. 147, 235-244.

Xu, J.Y., Wu, Y.X., Shi, Z.H., Lao, L.Y., Li, D.H., 2007. Studies on two-phase co-current air/non-Newtonian shear-thinning fluid flows in inclined smooth pipes. Int. J. Multiph. Flow 33, 948-969.

Zhang, J., Xu, J.Y., 2016. Rheological behavior of oil and water emulsions and theirs flow characterization in horizontal pipes. Can. J. Chem. Eng. 94, 324-331.

Zhang, J., Xu, J.Y., Gao, M.C., 2014. Experimental investigation on yield stress of waterin-heavy crude oil emulsions in order to improve pipeline flow. J. Dispers. Sci. Tech. $35,593-598$.

Zhang, C.M., Zhao, H.J., Xiao, Q.H., Li, J.Y., 2005. New model of heavy oil viscosity prediction. J. Yangtze Univ. Nat. Sci. 7, 216-218 (In Chinese). 